\title{
Teaching Second Languages for the Workplace
}

\author{
Jonathan Newton and Ewa Kusmierczyk
}

Workplace culture and organization are evolving as they adapt to globalization and rapid technological development. Likewise, the nature and role of workplace language and the literacy demands of work are changing in the face of increasingly multicultural workplaces and global communication networks. Among these changes, recent research has highlighted the role that informal modes of interpersonal communication play in the functioning of the modern workplace. Successful participation in such interactions is seen as not just a question of fitting in socially, but of doing work through talk. Ethnographic research in the workplace has stressed the importance of understanding language by viewing it within its social setting and understanding the interactional norms of particular communities of practice. Research into language programs for the workplace reflects this shift in emphasis. In contrast to research in the field of language for specific purposes on the specialized vocabulary and formal registers of particular professions, a growing body of research focuses on teaching and learning the language of routine workplace interactions. This article reviews current research into the nature of workplace language, noting in particular the contributions from ethnographic and language socialization research. It then discusses research into four aspects of the content of language programs for the workplace: employability skills, interpersonal communication, intercultural and critical language awareness, and teaching focused on the employment interview.

In writing this review article we find ourselves working in a somewhat crowded space between the two related fields of language for specific purposes (LSP) and language socialization. Our review foregrounds language socialization perspectives (Duff, 2005, 2008; Roberts, 2005, 2010) because much teaching for the workplace occurs within or in close alliance with workplaces and so lends itself to the socially situated orientation that this field provides. We also focus on recent research into the nature of workplace language, especially research pursued for the explicit purpose of informing language teaching for the workplace.

We see four interconnected trends emerging from recent research on language teaching for the workplace, each of which we address in this review. First, a growing body of research uses situated, ethnographic methods of data 
collection for the purposes of describing workplace discourses in particular settings, understanding the social processes typical of these settings (e.g., Franklin, 2007), and highlighting the experiences of new workers in the workforce (e.g., Warriner, 2010). Second, research increasingly focuses on interpersonal, informal workplace communication (e.g., Yates, 2008). This reflects an awareness of how important but challenging the language of routine interactions is for those seeking to participate in workplaces in which they are seen to be culturally or linguistically peripheral (Holmes, 2005b). Such an emphasis stands in stark contrast to a traditional LSP focus on the technical, formal language of particular jobs or professions. It also lends itself to a focus on issues of language and power (Fairclough, 2001) and the intercultural dimensions of interaction (Tomalin, 2009). The third trend, and one that mirrors the attention to interpersonal communication in the workplace noted earlier, is toward pedagogic approaches that prioritize awareness raising (Newton, 2007), including critical language awareness (Guo, 2009) and development of analytic skills for unpacking and of sensitivity to the sociopragmatic dimensions of communication in particular workplace settings (Holmes, 2005a; Riddiford \& Newton, 2010; Yates, 2008). It should be noted that such developments aim to complement rather than replace learning of the specialized vocabulary and formal registers of a chosen vocation. The fourth and final trend involves research into the discursive requirements of the employment interview and the challenges that intercultural interviews pose, particularly interviews involving migrants or ethnic minority candidates. The growing body of research in this area is informed by critical perspectives (Roberts \& Campbell, 2006) and both draws on and contributes to all four of the trends just described here.

\section{LANGUAGE, LITERACY, AND THE CHANGING NATURE OF WORK}

Rapid social and technological change is transforming the face of work in Western societies. As Roberts (2005) noted, this transformation includes a move toward high-technology manufacturing; service-oriented industries; and new forms of organization such as self-directed teams, more flexible work practices, more multitask working, and flatter organizational structures. These changes in turn produce new forms of workplace communication as people are required to adopt new ways of writing, speaking, and making meaning through multimedia and through an ever diversifying range of electronic communication tools (Vertovec, 2007). An increasingly common feature of new electronic literacies is highly intertextual texts involving bits of text from different sources (Duff, 2005) and linkages across different media. Duff (2008) saw implications for language and communication in which

new forms and means of (tele)communication in the service industries and other professions, coupled with intensive globalization, migration, and market pressures, are associated with the development of new literacies, new measures of sociolinguistic control and new expectations about language learning and use. (p. 268) 
Contradictions emerge as workplaces become increasingly multicultural and multilingual (Vertovec, 2007), while simultaneously experiencing the homogenizing pressure of English as a lingua franca. Many multinationals have adopted a policy of using English for company communication, a policy that has had a marked impact on demand for workplace language programs (Chivers, 2010). For example, Rakuten, Japan's top online shopping site, switched its in-house language from Japanese to English, a decision explained in the following way by Chief Executive Hiroshi Mikitani:

The language used for the process of sharing information internationally is something everyone in the world can understand, which is not Japanese, unfortunately. If you cannot follow internationalization and a language shift to English, you will find no place to work in Rakuten. (Wallace, 2010, p. 24)

Indeed, as Duff (2005) has noted, English is now the international norm for electronic intercultural communication among nonnative users of English. These changes, coupled with an increasingly globally mobile workforce across all sectors of the economy, ensure growing demand for workplace training and language courses. In many cases these link directly to the workplace through job internships and integrative cooperative experiences, on-site training, and professional development, all of which reflect a trend toward what Vertovec (2007) described as a blurring of distinctions between (higher) education and work. This trend is particularly important for the teaching of language for the workplace. As Roberts (2005) noted,

Although thousands of English language courses have been run in workplaces, it is the opportunity to use the workplace environment as a continuing site of language development that is central to most workplace projects. .. . The "novice" English speaker learns to use language as a social practice and through language learns the sociocultural knowledge that is "wired into" language use. (p. 118)

Burt and Mathews-Aydinli (2007) identified a number of potential advantages of in-situ learning including ease of scheduling, authenticity of content, and cultivation of a positive work environment. They also noted significant challenges, including unrealistic expectations about language development, learner discomfort when classes are viewed as projecting a deficit attitude, demands on teachers to be knowledgeable about both language pedagogy and workplace-specific tasks, tension between training and education goals, and lack of opportunities for gaining credentials.

\section{EVIDENCE-BASED WORKPLACE LANGUAGE TEACHING}

Research into workplace discourse is increasingly focused on the workplace as a holistic communicative environment and on the communicative ideology of the 
workplace, rather than on needs analysis and course evaluations as in earlier studies (Roberts, 2005). This change reflects the influence of the growing field of language socialization research focused on the workplace (Duff, 2008). The range of settings being researched in this way has expanded to include physics labs, hospitals, legal practices, hairstyling salons, call centers, manufacturing plants, professional workplaces, and government and civil service (Duff, 2008). This trend for situated research dovetails nicely with a call from applied linguists for content in workplace language programs based more firmly on empirical and ethnographic description and analysis of patterns of actual language use in specific workplaces and sectors (Duff, 2005; Holmes, 2005b; Holmes \& Riddiford, 2009; Newton, 2007; Yates, 2010b). It also concurs with the opinions of employers according to a recent study involving a survey of 245 supervisors and executives in 24 U.S. manufacturing companies with at least 150 employees. The study found that a number of companies were dissatisfied with the results of English language classes because the classes focused too much on decontextualized language study and failed to address language needs directly relevant to the workplace (Duval-Couetil \& Mikulecky, 2006, cited in Burt \& Mathews-Aydinli, 2007).

Yates (2010b) called for "an approach to instruction that draws on empirical evidence from a range of perspectives so that non-native speakers can understand patterns of language use, how these relate to cultural values, and how individuals actually draw on them in context" (p. 109). Similarly, Duff (2005) argued for shaping workplace literacy education through "situated research," which seeks to understand the social practices accompanying texts and that exposes students to "the specific genres that fulfill particular communicative functions within particular settings" (p. 358). For example, research by Waldvogel (2005) has shown how the conventions for e-mail correspondence, including level of formality, times when e-mail is used in preference to face-to-face conversation, and ways of signing off an e-mail, vary tremendously across workplaces. Similarly, Holmes and Stubbe (2003) showed how humor and small talk are used differently across workplace communities of practice and how these and other features of workplace talk reflect and construct social values such as those concerning power and status. Duff (2005) eloquently outlined the purpose and vision underlying this approach:

Examining the contextualized experience of individuals interacting in different languages (L1, L2, or L3) in work environments and closely examining the new literacies and competencies required for work provides a basis for improving work conditions, productivity, mutual understanding, and, it is hoped, cooperation within and among employees and management teams. (p. 346)

Ethnographic approaches to data collection serve this purpose well, as reflected in some recent studies (Arakelian, 2009; Franklin, 2007; Vickers, 2007; Warriner, 2010). These studies share a commitment to understanding the experience of new workers in specific multicultural and multilingual work settings in order to assist them to participate fully in their chosen places of work. Warriner (2010), for example, used ethnographic methods such as participant 
observation, interviews, and document collection to explore the relationship between work processes and learning processes in the lives of three refugee women transitioning from an adult ESL (English as a second language) program into work in a North American city. She found that while the women successfully entered the workforce and moved from peripheral to legitimate membership of the communities of practice, their low-skill menial jobs were likely to exclude and marginalize them from participation in other more economically and socially advantageous workplace communities.

Transition into full participation in the workplace is also investigated by Vickers (2007). She carried out a detailed analysis of the interactions that led to the socialization of a peripheral, nonnative speaker member (named Ramelan) of a team of engineering students in a capstone design course into core membership of the team. Socialization relied on three main factors: access to observation of core members interacting; guidance from core members both in the lab and in the team meetings; and opportunities for successful participation in the work of the team. Vickers argued that Ramelan's language behavior changed (i.e., he adopted the team's way of talking) as a "product of learning to think, design, and talk like a competent engineer" (p. 637).

A related approach, appreciative inquiry (Hammond, 1996), acknowledges that the precise form that effective communication takes depends on who is talking to whom, and in what kind of context; it depends on what each is trying to achieve in the interaction; and it depends on their workplace culture or the interactional norms of their particular community of practice. As its name suggests, appreciative enquiry focuses on the skills and strategies that underpin successful communication. Holmes et al. (2011) reported on a research project being carried out by the Wellington Language in the Workplace Project using this approach to identify features of successful communication at work. When workers from different social and cultural backgrounds engage in workplace interaction, there is considerable potential for mismatches in their assessments of the relative importance of some of these components, which can result in misunderstandings, including unintended offence (Clyne, 1994; Holmes, 2005a). This research has led quite naturally toward an exploration of the lessons that could be learned about successful interaction for the benefit of new employees in a workplace, especially those who may be fundamentally disadvantaged when they join a new society because of their lack of social power as well as their unfamiliarity with societal norms. Consequently, this kind of approach is designed to explore ways to empower these people, rather than attempt to make them fit (cf., Eades, 2004; Pennycook, 2001; Rampton, 2001). Such approaches help people to undertake their own sociolinguistic analyses of the relative weight of dimensions such as power, social distance, and formality, for example, in order to decide how to relate comfortably to others at work. Let us give an example of how this might be applied to classroom practice. A class is given in which a challenging workplace scenario is created that requires the students, in a particular workplace role, to respond to a situation via e-mail. In their roles, the students each craft and send an e-mail to their teacher. The replies are collated by the teacher and shared with the students in a subsequent class along with the teacher's response to the same scenario and perhaps responses from others beyond 
the class. These are discussed and compared with the purpose of identifying different language choices, why these were made, and what impact they might have. From this discussion, students develop awareness of the repertoire of discursive options available to them and what impact these options are likely to have. And so rather than describing and learning to replicate workplace genres as in a more traditional LSP approach, this approach encourages a critical and constructivist engagement with the process of learning ways of communicating at work.

\section{WHAT IS BEING TAUGHT?}

The following sections survey scholarship on four aspects of the content of workplace language courses: employability skills, interpersonal communication, intercultural and critical language awareness, and teaching focused on the employment interview. This list is necessarily selective. We think, however, that it captures the more important and interesting areas addressed in recently published research in this area.

\section{Teaching and Learning Employability Skills}

Employability skills come under a variety of guises, referred to as core or key skills in the United Kingdom; workplace competencies in the United States; essential skills in Canada; core competencies in New Zealand; and key competencies, generic skills, or employability skills in Australia. Broadly speaking, these skills include basic numeracy and literacy, use of technology, communication and people skills, thinking skills such as problem-solving skills, and personal skills and attributes such as responsibility and time management (Yates, 2008). The overlap with language, literacy, and communication skills makes these skills an important component of many workplace-based language/skills programs. As Yates (2008) noted, English requirements are no longer based on proficiency only; they contain a range of other skills such as sociopragmatic competencies, flexibility, and ability to communicate in diverse settings:

New arrivals entering the job market face the challenge of not only having English language and literacy skills commensurate with technical demands of the job, but also of understanding how to operate in a new work culture where the norms and expectations relating to good communication and how teams work together may be very different. (p. 13)

Employability skills are frequently seen by employers as at least as important if not more so than job-specific technical skills (Yates, 2008). Those seeking employment, or in the early stages of new employment, also appear to value employability skills. Knight (2009) carried out a small-scale study on the effectiveness of a business internship program in preparing a small group of six students for participating in the global workforce. The internship took place within 
a mock domestic business company set up in a Japanese university. Reponses to a 43-item questionnaire showed that while most of the students ranked such employability skills as teamwork, interpersonal skills, problem solving, marketing expertise among the five most valuable benefits of the internship, only one identified improved English proficiency. This low ranking for English was despite the fact that all meetings in the internship were conducted in English.

Yates (2010c) investigated the experience of newly arrived migrants to Australia in the community and in the Adult Migrant English Program (AMEP) with the aim of identifying the English language needs typical of early settlement. The findings of this research highlight the need for programs to link language instruction to generic workplace skills training, and for program content to be based on the specific language requirements of particular occupations or industries.

\section{TEACHING AND LEARNING SOCIAL, INTERACTIONAL TALK}

The second trend is that research into language teaching for the workplace is focusing on the nature and roles of informal, interpersonal workplace communication. This reflects a trend toward less formal forms of discourse in Western workplace contexts and a shift in focus in language programs from front-of-house communication (such as service encounters and doctor-patient interactions) to nontechnical, social, interpersonal behind-the-scenes talk (such as on the factory floor or in an office) (Yates, 2010a). More than ever in the workplace, success depends not only on the ability to perform work but also on managing social aspects of interaction at work in order to participate fully in the life of the workplace (Holmes, 2005a). As Myles (2009) noted, "the formal systems of command with written memos, formal letters and supervisors' orders have been replaced by multi-discipline or multi-function teams, which is much more dependent on informal, oral and interpersonally sensitive written forms, such as email messages" (p. 4). This trend is reflected in research on private discourse in the workplace, such as research on language in routine interactions (Holmes, 2005b), on the discourse of particular workplace communities of practice (Myles, 2009), and on speech acts (Yates, 2010b; Yates \& Springall, 2010).

Three small-scale studies have shown that a focus on informal, oral communication is also seen as a priority by those required to use a second language at work. Myles (2009) interviewed four ESL interns (engineering graduates) and their associates (e.g., tutors, trainers, employers) over 6 months at a large computer software company. The workplace was described as having an "intensely oral culture" (p. 60) that required participation in social talk and the ability to use and understand colloquial expressions, cultural connotations, and different styles. Not surprisingly, the interns all reported that oral communication was the most challenging aspect of language use at work. Similarly, Qian (2009) found that novice engineers in Hong Kong viewed the need to improve their oral English as more important than the need to improve their writing skills for technical report writing (see also Cooper, 1998). Wood (2009) also reported how engineering students from non-English-speaking backgrounds often struggle to 
cope with the communication demands of an English-speaking workplace. By chance rather than design these three studies all focus on the engineering profession. Whether other professions manifest the same priorities is a matter for further research.

As this research shows, the sociopragmatic dimension of talk at work is particularly challenging for migrants or people functioning in a second language and culture. For instance, choosing an appropriate level of directness in statusdifferentiated interactions involving requests and refusals (Holmes \& Stubbe, 2003) or participating in small talk (Holmes, 2005b) requires sensitivity to crosscultural differences in the way talk functions in different work settings. In the case of small talk, Holmes suggested analyzing small talk in local soap television shows (presumably focusing on workplace interactions in these shows) and performing role-plays as a way to sensitize new migrants in some of the ways that small talk functions in a particular cultural setting.

One approach to researching the sociopragmatic dimension of talk at work is to focus on particular speech acts, with requests being a particular favorite in recent research. Riddiford and Joe (2010) tracked the development of request strategies in English by skilled migrants enrolled in a blended classroominternship workplace training program. Data collection involved pretest, midpoint, and posttest assessment using discourse-completion tests (DCTs) and role-plays; recordings of participants interacting in workplaces; and final interviews. The study found that both awareness of aspects of the sociopragmatics of requests in New Zealand English and communicative behaviors showed marked development over the 12 weeks. End-point DCTs revealed greater use of internal and external modifiers (e.g., openers such as I wonder if you could ... . ? and preparators such as Can I have a quick word). End-point role-plays showed greater responsiveness to addressees through small talk, increased use of personal names, and more turn-taking. Riddiford and Joe argued that these gains point to the benefits of three salient features of the program: (a) explicit pragmatic instruction alongside workplace placement, (b) opportunities to analyze recordings of authentic workplace conversations, and (c) sufficient time to develop awareness of sociopragmatic features of workplace communication in a particular setting.

Also focusing on request speech acts, Wigglesworth and Yates (2007) investigated how native English speakers (NESs) in Australia and nonnative English speakers (NNESs) enacted a range of complex role-play requests. The aim was to identify the pragmalinguistic devices and sociopragmatic values underpinning NESs' performance, to identify what learners find problematic about the task, and, from both these sources, to suggest priorities for teachers preparing learners for similar complex request situations in the workplace. The authors found that in contrast to the NNESs, the NESs "asserted solidarity rather than acknowledged hierarchy" (p. 793) in their request strategies. They did this through, for example, using down toners (e.g., "This is bit of a problem."); hedges (e.g., "I could be wrong, but I think it's a bad idea."); and other pragmatic devices to establish rapport, informality, and apparent egalitarianism. The value of this research is that it offers insights that can assist both native and nonnative English speakers in hierarchical workplace relationships to understand and adapt 
to differences in each other's discourse style in relation to this important and potentially face-threatening speech act.

Speech acts have also been a focus of materials developed for teaching workplace communication in English to migrants from non-English-speaking backgrounds. Yates and Springall (2010) drew on Wigglesworth and Yates's (2007) research, discussed earlier, to propose an approach to designing materials for the purpose of equipping adult learners of English with successful request strategies for the workplace. Request speech acts warrant this attention because not only are they pervasive in the workplace, but they are also quite risky to perform (because they involve asking someone to do something) and, in English, involve a wide range of devices and strategies for mitigating imposition and building rapport. Riddiford and Newton (2010) also focused on speech acts in a book of teaching materials designed to prepare migrant professionals for a work placement and for eventual employment in their chosen professions (see also Holmes \& Riddiford, 2009). The book focuses on facethreatening speech acts such as requests, refusals, disagreements, complaints, and apologies. A unique feature of this book-and one that connects it closely to research-is that it incorporates (re)recordings and transcriptions of naturalistic, authentic interactions from various workplaces. This is different from the usual practice in workplace communication textbooks of using made-up or elicited samples of workplace communication. The process of obtaining and transcribing authentic workplace talk and selecting and adapting samples for use in a workplace language program is challenging. This is because, as Newton (2007) observed, the situated nature of workplace conversations makes for "complex, idiosyncratic, unruly conversational artifacts that belie the perceived ease with which we all carry out conversations in our native language" (p. 520).

But drawing on naturalistic data is not the only way of ensuring fidelity in materials design. Yates (2008) reported on a detailed and rigorous research project on the teaching of employability communication skills to adult migrants in Australia for the AMEP settlement program, out of which four sample teaching units were developed. In each unit, the samples of workplace language provided were based around role-plays carried out by NESs. Yates argued that this approach allowed the materials writers to maintain some control over the content of the dialogues, while also ensuring that the features they were interested in were included. Whether the data are naturalistic or elicited, a common feature of materials design in both approaches is a commitment to authenticating the language models being used and providing opportunities for learners to analyze, reflect on, and try out what they have learned. A contentious issue is the extent to which these approaches treat NES interactions as prototypical. How does this align with the increasingly multilingual and multicultural workplace (Kramsch \& Whiteside, 2008)? Does it assume that NESs are fully pragmatically competent, in contrast to NNESs, who might actually be fully proficient and even more pragmatically capable in some cases? And to what extent are NES interactional norms preferred or even achievable targets? Such issues are central to the critical and intercultural approaches to workplace language teaching discussed in the following section. 


\section{Teaching and Learning for Intercultural and Critical Language Awareness}

Awareness raising is important both as a process and goal of language teaching designed to prepare learners for the workplace (e.g., Arakelian, 2009; Guo, 2009; Newton, 2007; Roberts, 2007; Yates, 2008) and especially in teaching focused on intercultural and critical language awareness. As Yates (2010a) argued, language teaching for the workplace needs to "equip learners with the analytic tools to research interactive practices for themselves" (p. 110). Holmes et al. (2009) described an ongoing project looking at just this. The project tracked the sociopragmatic skills of professional migrants transitioning from a workplace language course into internships and then into full participation in the workplace. In the course and internship, authentic interactional data and critical internship incidents were used to develop the analytical skills that enabled the migrants to select linguistic forms that enacted an authoritative identity when required, and to be supportive, collaborative, and collegial when they judged it appropriate.

Cross-cultural and intercultural workplace training is a large field in its own right, and one with obvious overlaps with language teaching and applied linguistics. A focus on intercultural awareness in workplace language programs naturally follows from a focus on social and interpersonal workplace discourse. Communication is replete with culturally shaped expectations and communicative norms (Kramsch, 2004); indeed, as Kramsch (1993) argued, every time we speak, we perform a cultural act. Intercultural competence is a key component of the influential Common European Framework of Reference (Council of Europe, 2001) and is now a major component of adult education (Feng, Byram, \& Fleming, 2009) and healthcare education. A number of recent studies and publications in this area focus on materials design and training implementation. Utley (2004) presented materials designed to encourage reflection on cultural differences in communication and on the underlying causes of these differences. Utley explicitly sought to raise learners' awareness of latent ethnocentricism by exploring their own culturally shaped values, assumptions, and beliefs. Guilherme, Glaser, and Méndez García (2009) described the development and evaluation of materials prepared as part of a pan-European project targeting adult learners in multicultural, professional workplaces. They also incorporated critical reflection, with a strong emphasis on dialogue and holistic, experiential learning. A reflective approach is also advocated by Tomalin (2009), who outlined a rationale for intercultural materials based on experiential learning and critical incident methodology. This approach is well suited to workplace-based training and education programs in which participants are able to reflect on critical incidents from their own recent work experience. Such reflective processes would ideally also involve managers and co-workers whose own workplace pragmatics may give rise to some of the critical incidents that this approach draws on.

Franklin (2007) sought to test the assumption underlying culture-general training that a contrastive approach to broad cultural differences (e.g., Hall, 1959; Hofstede, 2001) provides an appropriate basis for cross-cultural training. To do so, he used a case study involving self-report data from 26 German and British managers working together after a postmerger company integration. Franklin 
found that contrary to predictions based on cross-cultural studies, cultural differences were not necessarily experienced as difficult, and, overall, the difficulties that the managers did experience in their intercultural interactions could not be easily predicted or explained by a traditional cross-cultural analysis. Instead, Franklin argued for an emic approach that "examines one culture or pair of cultures, studies behavior in the culture from within the system using structures discovered by the analyst, the absence of an overall framework thus allowing cultures to be studied in their own right" (p. 278). Franklin proposed that this approach would provide authentic data that applied linguists and cross-cultural trainers could use to directly address the communication difficulties typical of particular situations.

Finally, Arakelian (2009) described an intercultural communication skills program delivered in 16 UK hospitals. The program aimed to facilitate integration of skilled migrant workers into work in the UK health sector. Arakelian argued that existing diversity-based training approaches (which involve sharing information about different ethnic and religious groups) are ineffective in changing attitudes and behavior because they are too information-focused and essentializing about broad-brush cultural differences. In contrast, the program advocated by Arakelian is skills-based and avoids a "rule-based performative model" (p. 175). Program methods include reflective diaries for structured reflection, ethnography, role-playing practice scenarios (critical incidents as the basis for role-play and scenario-based learning), and workplace-based assignments.

The few studies surveyed in the preceding paragraphs are part of a growing literature on interculturally focused workplace language teaching. They all share a reflective, awareness-raising pedagogy, and all but Utley (2004), which is designed as a generic resource, advocate experiential learning as a way of tapping into the language and practices of particular workplaces and communities of practice. Here again we see a marked shift away from teaching normative generic discourse patterns and toward developing sensitivity to communication patterns in particular workplace settings.

Closely allied to intercultural awareness is critical language awareness. A critical stance on teaching language for the workplace focuses on hegemonic processes and outcomes implicit in the competition between languages and in discriminatory employment practices based on linguistic difference (Guo, 2009; Warriner, 2010). Roberts (2005) highlighted the tension between approaches to training driven by the productivity goals typical of management and approaches focused on emancipatory goals. Ultimately, this is an issue of whether work related English Language training functions to benefit migrant workers or merely to corner them in low-paid unskilled jobs, Roberts argued that "if language training is only part of the hegemonic process that gives English absolute dominance and further marginalizes limited speakers of English, then it needs to be challenged" (p. 126). Similarly McAll (2003) claimed that

language competence . . . comes to be a convenient tool for discriminating against other language groups in an apparently "legitimate" way, since no one can deny the importance of language in order to function 
in areas of the labour market where language is necessary to the work process. (p. 249)

A critical perspective was taken by Guo (2009), who employed a qualitative, interpretative paradigm to examine data collected through interviews and naturalistic observation into the ways in which immigrant professionals are prepared for employment in Canada through an ESL program. Guo showed how an emphasis in the program on acquiring accentless pronunciation, anglicizing given names, and adopting aspects of the dominant Canadian culture all reflect a deficit, subtraction model of the immigrants' own cultures and languages. Guo argued that such employment preparation programs should move away from narrowly linguistic training and focus more on the language required in the workplace. Guo also called for a critical multiculturalism that challenges the deficit model of cultural difference and encourages immigrants to "develop critical language awareness in order to contend and change practices of domination and institutional racism" (p. 31).

\section{Teaching and Learning for Employment Interviews}

A critical perspective is particularly relevant to the employment interview. The discourse requirements of interviews have been identified as resulting in "persistent but intangible barriers" for ethnic minority groups (Roberts, Campbell, \& Robinson, 2008, p. 9). Research within this area has focused on identifying the highly specialized discursive requirements of the job interview and problems stemming from the gap between those requirements and performance by migrant/ethnic minority candidates. For example, in a two-part study on employment and promotion interviews, Roberts and Campbell (2006) and Roberts et al. (2008) showed how a disjunction between the discursive requirements of interviews and on-the-job language use and the practice of othering migrant identity both impede access to employment and promotion for ethnic minority candidates.

Problems in discursive performance are also the main focus of Sarangi and Roberts's (2004) study on interviews and exams in medical settings. They showed how the failure of an international candidate in an oral exam resulted not from professional competence but from misalignment in the way three modes of talk (professional, institutional, and personal experience) were managed by participants in the interview. The authors focused on different uses of contextualization cues by the interlocutors to signal and interpret the ongoing activity (Erickson \& Schultz, 1982). The problem was illustrated with an example of an exam with a Spanish candidate who failed to respond to signals that conveyed dissatisfaction of the interviewers with her answers. A similar, problemidentification approach was taken by Birkner and Kern (2004), who reported on differences in impression management leading to unsuccessful outcomes for the Eastern candidates in job interviews in Western Germany. These differences include self and other perspectives in talk and discursive organization of agreement and disagreement, which are subsumed under "different understandings of the genre" (p. 244). 
Not all research in this area has taken a critical perspective. An alternative approach based on "appreciative inquiry" (Hammond, 1996) has been adopted in a small number of studies that focus on the skills and strategies used by interview participants to shape the dynamics of the interview and to bring about positive outcomes. These studies have focused on, for example, discourse features that indicate co-membership and an analysis of how expertise and trust is negotiated between the candidate and the interviewer. For example, Kerekes (2006) examined successful interviews where potentially problematic moves were mitigated by compensatory strategies used by the candidates to build the interviewers' trust. Factors that appeared crucial for determining the outcome of the interaction for both majority group and minority group candidates included positive self-presentation and establishing solidarity and rapport with interviewers. What distinguishes Kerekes's approach is the notion of success as achieving an agreeable outcome to both participants rather than merely matching their cultural and linguistic backgrounds (p. 29). When operationalizing the notion of success, Kerekes pointed to the inaccurate assumption made in crosscultural studies that in order to be successful, a second language speaker needs to resemble the native speaker (NS) in performance. Indeed, Kerekes (2007) argued that it is not important whether they perform similarly to successful NSs, but "that they perform in such ways as to have similarly successful results to those of their successful NS counterparts" (p. 1945).

The creation of co-membership was also discussed by Lipovsky $(2006,2008)$, who examined how NES candidates negotiated their skills and professional experience in interviews carried out in Australia in French for an academic post in France. Lipovsky showed how the candidates' lexicogrammatical choices contributed to the construction of solidarity between the interview participants and influenced the interviewers' positive or negative impressions of the answer, and thus of the candidate. In a small-scale study focusing on the interviewer, Lim, Winter, and Chan (2006) investigated the ways that interviewers could mitigate negative bias in their own judgments in intercultural interviews. These included interviewers developing rapport with candidates prior to the formal beginning of an interview and discussing their different experiences and expectations concerning interviews. Both strategies led to more successful interview outcomes. The Lim et al. recommended that candidates prepare for interviews by making explicit comparisons between cultures in order to highlight the implicit demands of interviews in the target cultural setting. Similarly, Louw, Derwing, and Abbott (2010) provided an example of a training module that highlights aspects of pragmatic performance for helping migrants in Canada to improve their interview skills. They stressed the need for access to authentic models that provide learners with examples of successful communication strategies. Although they did not expect learners to imitate NS pragmatic behaviors, they nevertheless argued that such models are important because learners "are expected to communicate according to established conventions, and knowledge of those conventions should be made available to them" (Louw et al., p. 754).

The literature on interviews reviewed in the preceding paragraphs highlights the need for both critical and appreciative perspectives and for both candidates and interviewers or employers to work on reducing barriers to success in 
intercultural interviews. From a critical perspective, those involved in teaching interview skills can focus on power inequalities and implicit forms of discrimination in intercultural interviews. At the discursive level, guided analysis of the conventional interview schema in the target setting and the candidate's culture offers a way of highlighting differences and similarities and of identifying interview strategies which promote positive interview outcomes. A blend of critical and appreciative approaches acknowledges the unique character of an intercultural job interview in which the candidate does not necessarily have to imitate the native performance in order to win the interview game.

\section{EVALUATING WORKPLACE LANGUAGE PROGRAMS}

A number of studies have investigated the effectiveness of workplace language teaching (Arakelian, 2009; Benseman, 2010; Ekkens \& Winke, 2009; Guilherme et al., 2009; Riddiford \& Joe, 2010; Yates, 2010a). Only one of these, Ekkens and Winke (2009), focused explicitly on the nature of evaluation of workplace language programs. Ekkens and Winke investigated the efficacy of standardized tests and alternative assessment in the form of learning journals for measuring learning in a 10-week workplace English language program. In this program 21 learners took the standardized tests (pre and post) and kept learning journals. Results of the two tests stood in stark contrast. Whereas the standardized tests showed marginal nonsignificant gains, the learning journals reported gains in listening and reading and demonstrated improvements in a range of other areas including performance on job-related English tasks, self-confidence, willingness to communicate, and motivation. This study highlights the mismatch between standardized tests of generic language proficiency and the goals of workplace courses, which are very often customized to address quite specific job requirements in particular workplaces. It also highlights the value of nonstandard forms of assessment for revealing a broader view of the learning outcomes of such programs.

Other studies focusing on the effectiveness of programs in delivering intended outcomes have been discussed elsewhere in this review. Two that have not been discussed warrant mention here. Yates (2010a) reported on an extensive investigation into the fit between the goals of an Australian migrant on-arrival settlement program and migrants' real-world experiences. The research involved multiple forms of ethnographic data collection over a 12-month period, including interviews, classroom observation, analysis of classroom materials, samples of assessment, and recordings of participants in a range of settings outside the classroom. Yates found a generally good fit between the program goals and participants' needs, as well as generally successful uptake of skills necessary for settlement and work in Australia.

Finally, Benseman (2010) provided a short report on the effect of a language, literacy, and numeracy program in a New Zealand factory setting. Self-report data indicated transfer of skills was taking place through the program not only in terms of the improved ability of participants managing paperwork and accuracy and efficiency with measurements and calculations, but also in terms of 
oral communication at work, and beyond the workplace. Among the factors that contributed to these results, Benseman identified the priority given to teaching content based on both the company's and individual's needs analysis, and opportunities to contextualize the teaching content, use realia, and make concrete links between skills being taught and their application.

\section{CONCLUSIONS}

The workplace itself does not always deliver the opportunities for language socialization that might be expected. In blue collar workplaces, noisy working environments, isolation, and clustering of first language culture groupsin particular workplaces and in teams within these workplaces-all constrain language learning opportunities (Duff, 2008; Yates, 2010b). Even in the increasingly globally mobile professional sector (Guo, 2009), evidence suggests that intercultural and sociopragmatic skills in multilingual contexts are difficult to acquire without explicit, guided attention (Franklin, 2007; Guilherme et al., 2009; Guo, 2009; Holmes, 2005b). Workplace programs that couple work and education can address these gaps. Such a coupling offers the obvious advantages of teaching the specific language needed for successful participation in particular workplaces and using the experience of learners in that workplace as an instructional resource. Furthermore, such an approach creates a congruence between the worlds of workplace language teachers and applied linguistics researchers. Both share an interest in the way language is used in particular workplace settings. For both, ethnographic methods offer a valuable tool for accessing and understanding this language. Both also share an emancipatory vision-a vision that, on the one hand, seeks to empower and equip people for fuller participation in work in multilingual and multicultural workplaces and, on the other, to challenge hegemonic processes and discourses in the workplace. In its groundbreaking work, the New London Group (2000) expressed this vision: "The role of pedagogy is to develop an epistemology of pluralism that provides access without people having to erase or leave behind different subjectivities" (p. 18). As highlighted in this review, recent research drawing on language socialization and intercultural and critical language awareness perspectives offers pedagogic tools and insights that can help the teaching of second languages in and for the workplace to achieve these important multicultural objectives.

\section{ANNOTATED BIBLIOGRAPHY}

Duff, P. A. (2008). Language socialization, higher education, and work. In P. A. Duff \& N. H. Hornberger (Eds.), Encyclopedia of language and education: Vol. 8. Language socialization (pp. 257-270). Boston, MA: Springer Science+Business Media.

Although only 14 pages long, this chapter is a highly informative overview of language socialization in work and higher education. Duff described recent trends in work practices and the changing discourse demands of work. She looked at the implications of these changes for the multicultural workplace, the induction into the workplace by immigrants, and the transition from education to work. The insights into 
workplace socialization offered by this chapter make it a valuable read for teachers, trainers, and course designers.

Feng, A., Byram, M., \& Fleming, M. (Eds.). (2009). Becoming interculturally competent through education and training. Bristol, UK: Multilingual Matters.

This edited collection describes research on interculturally informed training and teaching in a range of workplace settings, mostly within the European context. The chapters offer a wealth of examples of intercultural training in practice and bring to the fore the voices of teachers and learners. The book also explores the theoretical debates and conundrums that emerge within and between education and training, not least when culture is addressed.

Yates, L. (2008). The not-so generic skills: Teaching employability communication skills to adult migrants. North Ryde, NSW, Australia: AMEP Research Centre, Macquarie University on behalf of the Department of Immigration and Citizenship.

This publication reports on research conducted into preparation for the workplace through the Australian Adult Migrant English Program (AMEP), which provides English language instruction for newly arrived migrants to Australia. The research involved two projects. The first project, Employability Skills for Professional Workers, investigated the employment-related needs and experiences of learners who had completed an AMEP course and found work. The project investigated the particular skills and knowledge that helped project participants to get and keep their jobs, as well as areas of difficulty they experienced in the workplace. The second, the Communication Skills Project, investigated the nature of routine workplace interactions and drew on insights and data from this research for developing and trialing classroom materials for language teaching relevant to the workplace. This report demonstrates effective synergies between research into workplace language and classroom practice.

\section{REFERENCES}

Arakelian, C. (2009). Professional training: Creating intercultural space in multi-ethnic workplaces. In A. Feng, M. Byram, \& M. P. Fleming (Eds.), Becoming interculturally competent through education and training (pp. 174-193). Bristol, UK: Multilingual Matters.

Benseman, J. (2010). Transferring literacy skills in the workplace. Reflect, 13, 9-11.

Birkner, K., \& Kern, F. (2004). Impression management in East and West German job interviews. In H. Spencer-Oatey (Ed.), Culturally speaking (pp. 255-271). London, UK: Continuum.

Burt, M., \& Mathews-Aydinli, J. (2007). Workplace instruction and workforce preparation for adult migrants. Retrieved from CAELA Web site: http://webdev.cal.org/ development/CAELA/esl_resources/briefs/WorkplacePrep.pdf

Chivers, N. (2010). Tap a well of opportunities in Baku. EL Gazette, 369, 13.

Clyne, M. G. (1994). Inter-cultural communication at work: Cultural values in discourse. Cambridge, UK: Cambridge University Press.

Cooper, A. (1998). Mind the gap! An ethnographic approach to cross-cultural workplace communication research. In M. Byram \& M. Flemming (Eds.), Language Learning in Intercultural Perspective: Approaches through drama and ethnography (pp. 119-142). Cambridge, UK: Cambridge University Press.

Council of Europe. (2001). Common European framework of reference for languages. Cambridge, UK: Cambridge University Press.

Duff, P. A. (2005). Thinking globally about new literacies: Multilingual socialization at work. In J. Anderson, M. Kendrick, T. Rodgers, \& S. Smythe (Eds.), Portraits of literacy across families, communities, and schools (pp. 341-362). Mahwah, NJ: Erlbaum. 
Duff, P. A. (2008). Language socialization, higher education, and work. In P. A. Duff \& N. H. Hornberger (Eds.), Encyclopedia of language and education: Vol. 8. Language socialization (pp. 257-270). Boston, MA: Springer Science+Business Media.

Eades, D. (2004). Understanding Aboriginal English in the legal system: A critical sociolinguistics approach. Applied linguistics, 25, 491.

Ekkens, K., \& Winke, P. (2009). Evaluating workplace English language programs. Language Assessment Quarterly, 6, 265. doi:10.1080/15434300903063038

Erickson, F., \& Schultz, J. J. (1982). The counselor as gatekeeper: Social and cultural organization of communication in counseling interviews. New York, NY: Academic Press.

Fairclough, N. (2001). Language and power (2nd ed.). Harlow, UK: Longman.

Feng, A., Byram, M., \& Fleming, M. (Eds.). (2009). Becoming interculturally competent through education and training. Bristol, UK: Multilingual Matters.

Franklin, P. (2007). Differences and difficulties in intercultural management interaction. In H. Kotthoff \& H. Spencer-Oatey (Eds.), Handbook of intercultural communication (pp. 263-284). New York, NY: Mouton de Gruyter.

Guilherme, M., Glaser, E., \& Méndez García, M. (2009). The pragmatics of intercultural competence in education and training: A cross-national experiment on "diversity management." In A. Feng, M. Byram, \& M. Fleming (Eds.), Becoming interculturally competent through education and training (pp. 193-210). Bristol, UK: Multilingual Matters.

Guo, Y. (2009). Racializing immigrant professionals in an employment preparation ESL program. Cultural and Pedagogical Inquiry, 1, 40-54.

Hall, E. T. (1959). The silent language. New York, NY: Anchor.

Hammond, S. A. (1996). The thin book of appreciative inquiry. Plano, TX: Thin Book.

Hofstede, G. (2001). Cultures consequences: International differences in work-related values (Abridged). Newbury Park, CA: Sage.

Holmes, J. (2005a). Socio-pragmatic aspects of workplace talk. In Y. Kawaguchi, S. Zaima, T. Takagaki, K. Shibano, \& M. Usami (Eds.), Linguistic informatics-State of the art and the future: The first international conference on linguistic informatics (pp. 196-220). Amsterdam, the Netherlands: John Benjamins.

Holmes, J. (2005b). When small talk is a big deal: Sociolinguistic challenges in the workplace. In M. H. Long (Ed.), Second language needs analysis (pp. 344-372). Cambridge, UK: Cambridge University Press.

Holmes, J., Joe, A., Marra, M., Newton, J., Riddiford, N., \& Vine, B. (2011). Applying linguistic research to real world problems: The case of the Wellington Language in the Workplace Project. In C. Candlin \& S. Sarangi (Eds.), Handbook in applied linguistics: Communication in the professions (pp. 533-549). Berlin: Mouton de Gruyter.

Holmes, J., Marra, M., Newton, J., Joe, A., Riddiford, N., \& Vine, B. (2009). Enhancing socio-pragmatic skills among professionally qualified workers. New Zealand Studies in Applied Linguistics, 15, 38-46.

Holmes, J., \& Riddiford, N. (2009). Talk at work: Interactional challenges for immigrants. In V. K. Bhatia, W. Cheng, \& B. Du-Babcock (Eds.), Language for professional communication: Research, practice \& training. Hong Kong: Asia-Pacific LSP and Professional Communication.

Holmes, J., \& Stubbe, M. (2003). Power and politeness in the workplace: A sociolinguistic analysis of talk at work. London, UK: Longman.

Kerekes, J. (2006). Winning an interviewer's trust in a gatekeeping encounter. Language in Society, 35, 27-57. doi:10.1017/S0047404506060027

Kerekes, J. (2007). The co-construction of a gatekeeping encounter: An inventory of verbal actions. Journal of Pragmatics, 39, 1942-1973.

Knight, K. (2009). Business internship program development in light of professional communication research: Kevin's company at Kanda University of International Studies. In V. K. Bhatia, W. Cheng, B. Du-Babcock, \& J. Lung (Eds.), Language for professional communication: Research, practice \& training (pp. 235-249). Hong Kong: Asia-Pacific LSP and Professional Communication.

Kramsch, C. (1993). Context and culture in language teaching. Oxford, UK: Oxford University Press. 
Kramsch, C. (2004). Language, thought and culture. In A. Davies \& C. Elder (Eds.), The handbook of applied linguistics (pp. 235-261). Malden, MA: Blackwell.

Kramsch, C., \& Whiteside, A. (2008). Language ecology in multilingual settings. Towards a theory of symbolic competence. Applied Linguistics, 29, 645-671. doi:10.1093/applin/amn022

Lim, C. H., Winter, R., \& Chan, C. C. (2006). Cross-cultural interviewing in the hiring process: Challenges and strategies. Career Development Quarterly, 54, 4.

Lipovsky, C. (2006). Candidates' negotiation of their expertise in job interviews. Journal of Pragmatics, 38, 1147-1174.

Lipovsky, C. (2008). Constructing affiliation and solidarity in job interviews. Discourse \& Communication, 2, 411-432. doi:10.1177/1750481308095938

Louw, K. J., Derwing, T. M., \& Abbott, M. L. (2010). Teaching pragmatics to L2 learners for the workplace: The job interview. Canadian Modern Language Review [La Revue canadienne des langues vivantes], 66, 739-758. doi:10.3138/cmlr.66.5.739

McCall, C. (2003). Language dynamics in the bi- and multilingual workplace. In R. Bayley $\&$ S. Schecter (Eds.), Language socialization in bilingual and multilingual societies (pp. 235-250). Clevedon: Multilingual Matters.

Myles, J. (2009). Oral competency of ESL technical students in workplace internships. TESL-EJ, 13, 1-24.

New London Group. (2000). Introduction. In B. Cope \& M. Kalantzis (Eds.), Multiliteracies. Literacy learning and the design of social futures (pp. 9-37). London, UK: Routledge.

Newton, J. (2007). Adapting authentic workplace talk for workplace communication training. In H. Kotthoff \& H. Spencer-Oatey (Eds.), Handbook of intercultural communication (pp. 519-537). New York, NY: Mouton de Gruyter.

Pennycook, A. (2001). Critical applied linguistics: A critical introduction. In A. Davies \& C. Elder (Eds.), Handbook of applied linguistics (pp. 784-807). Malden, MA: Blackwell.

Qian, D. D. (2009). Using English for workplace communication: A study of novice professionals. In V. K. Bhatia, W. Cheng, B. Du-Babcock, \& J. Lung (Eds.), Language for professional communication: Research, practice, and training (pp. 270-285). Hong Kong: Asia-Pacific LSP and Professional Communication.

Rampton, B. (2001). Language crossing, cross-talk, and cross-disciplinarity in sociolinguistics. In N. Coupland, S. Sarangi, \& C. Candlin (Eds.), Sociolinguistics and social theory (pp. 261-296). London, UK: Pearson.

Riddiford, N., \& Joe, A. (2010). Tracking the development of sociopragmatic skills. TESOL Quarterly, 44, 195-205. doi:10.5054/tq.2010.215252

Riddiford, N., \& Newton, J. (2010). Workplace talk in action: An ESOL resource. Wellington, New Zealand: Victoria University of Wellington.

Roberts, C. (2005). English in the workplace. In E. Hinkel (Ed.), Handbook of research in second language teaching and learning (pp. 117-136). Mahwah, NJ: Erlbaum.

Roberts, C. (2007). Multilingualism in the workplace. In P. Auer \& L. Wei (Eds.), Handbooks of applied linguistics: Vol. 5. Handbook of multilingualism and multilingual communication (pp. 405-422). New York, NY: Mouton de Gruyter.

Roberts, C. (2010). Language socialization in the workplace. Annual Review of Applied Linguistics 30, 211-227.

Roberts, C., \& Campbell, S. (2006). Talk on trial: Job interviews, language and ethnicity. Research Report-Department for Work and Pensions, 344. Retrieved from http://research.dwp.gov.uk/asd/asd5/rports2005-2006/rrep344.pdf

Roberts, C., Campbell, S., \& Robinson, Y. (2008). Talking like a manager: Promotion interviews, language and ethnicity (Research Report No. 510). London, UK: Department for Work and Pensions.

Sarangi, S., \& Roberts, C. (2004). Discoursal (mis)alignments in professional gatekeeping encounters. In C. J. Kramsch (Ed.), Language acquisition and language socialization. New York, NY: Continuum International.

Tomalin, B. (2009). Applying the principles: Instruments for intercultural business training. In A. Feng, M. Byram, \& M. Fleming (Eds.), Becoming interculturally competent through education and training (pp. 115-131). Bristol, UK: Multilingual Matters. 
Utley, D. (2004). Intercultural resource pack. Cambridge, UK: Cambridge University Press.

Vertovec, S. (2007). Super-diversity and its implications. Ethnic and Racial Studies, 30, 1024. doi:10.1080/01419870701599465

Vickers, C. H. (2007). Second language socialization through team interaction among electrical and computer engineering students. Modern Language Journal, 91, 621-640. doi:10.1111/j.1540-4781.2007.00626.x

Wallace, R. (2010, July 8). Japan lost in translation. Australian, 24.

Waldvogel, J. (2005) The role, status and style of workplace email: A study of two New Zealand workplaces (Unpublished doctoral dissertation). Victoria University of Wellington, New Zealand. Wellington

Warriner, D. S. (2010). Competent performances of situated identities: Adult learners of English accessing engaged participation. Teaching and Teacher Education, 26, 22-30.

Wigglesworth, G., \& Yates, L. (2007). Mitigating difficult requests in the workplace: What learners and teachers need to know. TESOL Quarterly, 41, 791-803.

Wood, D. (2009). Preparing ESP learners for workplace placement. ELT Journal, 63, 323331.

Yates, L. (2008). The not-so generic skills: Teaching employability communication skills to adult migrants. North Ryde, NSW, Australia: AMEP Research Centre, Macquarie University on behalf of the Department of Immigration and Citizenship.

Yates, L. (2010a). Language training and settlement success: Are they related? North Ryde, NSW, Australia: AMEP Research Centre, Macquarie University.

Yates, L. (2010b). Speech act performance in workplace settings. In A. M. Martinez Flor \& E. U. Juan (Eds.), Speech act performance: Theoretical, empirical and methodological issues (pp. 109-126). Amsterdam, the Netherlands: John Benjamins.

Yates, L. (2010c). Welcome to Australia: Social inclusion, opportunities for interaction and investment in English language learning for migrants. Paper presented at the 35th Applied Linguistics Association of Australia (ALAA) Congress, Queensland University, Australia. Brisbane

Yates, L., \& Springall, J. (2010). Soften up! Successful requests in the workplace. In D. Tatsuki \& N. Houck (Eds.), Pragmatics from research to practice: Teaching speech acts (pp. 67-86). Alexandria, VA: TESOL. 